\title{
Health Care in The Netherlands
}

\author{
Chris van Weel, Henk Schers, and Arno Timmermans
}

This article analyzes Dutch experiences of health care reform-in particular in primary care-with emphasis on lessons for current United States health care reforms. Recent major innovations were the introduction of private insurance based on the principles of primary care-led health care and including all citizens irrespective of their financial, employment, or health status; introduction of primary care collaboratives for out-of-hour services and chronic disease management; and primary care team building, including practice nurses. These innovations were introduced on top of a strong primary care tradition of family practices with defined populations based on patient panels, practice-based research, evidence-based medicine, large-scale computerization, and strong primary care health informatics. Dutch health reform redirected payment to support introduction of innovative health plans and strengthening of primary care to respond to public health objectives.

Five recommendations for US primary care follow from this Dutch experience: (1) a private insurance model is compatible with thriving primary care, but it must include all people, especially the most vulnerable in society, and espouse a primary care-led health care system; (2) patient panels or practice lists strengthen continuity of care and community orientation to focus on and respond to local needs;

(3) reward collaboration within primary care and between primary care, hospital care, and public health; (4) stimulate primary care professionals to exert their passion and expertise through participation in primary care research and development; and (5) health informatics should be primary care based, preferably adopting the International Classification of Primary Care. With these recommendations, it will be possible for the United States to obtain better population health for its population. (J Am Board Fam Med 2012;25:S12-17.)

Keywords: Health Care Reform, Integrated Health Care Systems, Netherlands, Primary Health Care

\section{The Health Care System}

In 1941, the Netherlands introduced the Sick Fund Law to improve the health of the Dutch population. Its basic principles were in keeping with recently promoted principles of health care $^{1}$ : care based on the prevailing science, universal coverage, equity in access, and cost effectiveness. Ever since, people are listed with a family physician (FP) who provides them health care and coordinates access to

This article was externally peer reviewed.

Submitted 7 July 2011; revised 7 November 2011; accepted 16 November 2011.

From the Department of Primary and Community Care, Radboud University, Nijmegen Medical Center, Nijmegen, The Netherlands (CvW, HS); and the Dutch College of General Practitioners, Utrecht, The Netherlands (AT).

Funding: none.

Conflict of interest: none declared.

Corresponding author: Chris van Weel, Department of Primary and Community Care, Radboud University Nijmegen Medical Center, 117-hag, PO Box 9101, 6500HB, Nijmegen, The Netherlands (E-mail: c.vanweel@elg.umcn.nl). specialized care. This leading role of primary care has remained the guiding principle, even after migration in 2006 to universal private insurance, whereby patients are covered by a single insurance company for their health care. ${ }^{2}$

Currently, the Dutch population of 16 million inhabitants is served by 8000 to $10,000 \mathrm{FPs}$, who are the point of entry for people to health care. Specialists and hospital care can only be accessed after referral by the FP. More than $95 \%$ of all episodes of care are completely covered in primary care, and FPs remain actively involved in the management of the remaining episodes of care. $^{3}$ A comparison of the effectiveness of the Dutch model of individual health care and public health estimated that primary care is responsible for $25 \%$ of the decline in premature mortality, slightly more than public health. ${ }^{4}$ Better integration between care for individual patients and management of population health is expected to 
yield further improvements in the health status of the population.

We believe the Dutch health system holds lessons for the United States from its experience of the last few decades and growing out of its move to new models of insurance, which are more like the US insurance market but with a focus on equity and population health and further strengthening of primary care.

\section{New Models of Clinical Care, Including Panels and Out-of-Hours Services}

The principle behind the 2006 revision was to introduce a market system with competition between providers. Insurers are considered the patient's broker in negotiating the best care for the best price. A strong point of the current Dutch health care system is that evidence-based health care policy ${ }^{5}$ has prevailed after the introduction of marketoriented reform. This includes universal coverage and primary care leadership. Another organizing principle is that individual FPs or FP practice groups have listed patient panels for which they bear population and personal health responsibility. The average list or panel size is 2250 to 2500 patients for a full-time equivalent FP and consists of people living in defined geographies. The list defines the population under care whereas population sociodemographics and other assessments define their needs for care and prevention. There is active monitoring of these needs and outcomes. These assessments have consequences for the composition of the practice team, in particular the tasks in which practice nurses engage. This will be further expanded on in the Primary Care Workforce section. Health professionals, practices, and hospitals play a leadership role in developing health care innovations. There has been a substantial investment in family medicine and primary care over the last 3 decades that bears fruit for the state of health care today. Investment in primary care research from the 1980 s onward ${ }^{6,7}$ has resulted in a strong collaboration between academia and family practice ${ }^{8}$ and output of high-quality research. ${ }^{9}$ This, in turn, made family medicine the leading force in evidence-based medicine, ${ }^{10,11}$ resulting in a strong societal position since the 1990s. Concepts of person-centered care and continuity of care have received a modern face lift through person-centered electronic medical records (EMRs). The 2006 health care reform had a specific focus on conserving these historic successful innovations.

The provision of after-hours care ("out of hours access") and the quality of these services were critically revised ${ }^{12}$ with the creation of FP regional "out of hours" consortia, through which FPs and practice staff rotate duties including evening, night, and weekend coverage for telephone consultations, urgent practice visits, and home visits. This organization secures around-the-clock availability of primary care and access to adequate support facilities, including access to each patient's EMR.

\section{Primary Care Workforce}

Until recently, most FPs were in solo practice, but the last few years have seen a rapid change to group practices and health centers. Currently, 30\% work solo, $30 \%$ in multidisciplinary health centers, and $40 \%$ in group practices ${ }^{2}$; it is important to note that solo practices and group practices do engage on a large scale in (multidisciplinary) collaborations (detailed later).

Professional assistants play a central role in the practice. This professional role was initially administrative but evolved into a professional support function akin to the physician assistant role in the United States. Practice assistants perform routine diagnostic and therapeutic interventions and serve as the patients' point of contact for health education and the booking of practice visits. On average there is a practice assistant for every FP.

Practice nurses usually have a professional nursing background. Practices employ them-from their practice overhead or through special arrangements with insurers-to design health programs based on the needs of their practice population. These often involve disease prevention, chronic care management, mental health services, frail elderly assessments, and care of families with young children. Under the new private insurance scheme, insurers should be keen to extend the payment for practice nurses because it would enable practices to further innovate services beyond the standard package. The insurers' interest is that this adds value to the health of their beneficiaries. This new role of insurers is currently in its early stages, but thus far they have been willing to respond to care performance and innovations developed by professionals.

Dutch reforms also have marked a shift from individual professionals to a team approach. Reflecting this shift, professional development, con- 
tinuous medical education, and the quality structure, supervised by the Dutch College of General Practitioners (DCGP), have moved from individual to team performance. ${ }^{10,11}$ This development underlines an important learning point: team building and responsibility is only possible when all partners work from the same principles such as patient centeredness, equity, evidence-based medicine, and cost-effectiveness. ${ }^{5,13}$

Practices interact with many other professionals in the community that are also part of the health system. Some of these are shared practice resources based, in the community:

- district nurses: provide home care in the community for elderly and chronically ill patients;

- midwives: deliveries in primary care account for $40 \%$ of the births, mainly by midwives who supervise pregnant women from the first trimester up until 10 days after delivery;

- physiotherapists: can be directly accessed by patients but often treat musculoskeletal problems after referral by the FP. An innovative development is their involvement in practice programs to enhance physical fitness;

- community pharmacists: collaborate with FP practices in the same catchment area, with whom they partner in "pharmacotherapeutic councils" to promote rational prescribing;

- psychologists, social workers, dieticians, podiatrists, and speech therapists; and

- occupational health physicians: traditionally independent, but strong incentives were recently created to link with primary care.

\section{Outcomes and Accountability}

The aging of the population and increases in chronic (co)morbidity present the main challenges for the Dutch health care system, as in the United States. One fifth of the Netherlands' population are immigrants, another source of challenges for the health system. ${ }^{2}$ Personal responsibility of people for their own health and better use of preventive services are essential. To serve the needs of the local population, it is important to connect practice initiatives for individual patients with population-based action, for example, in the field of promoting healthy foods or active lifestyles or in smoking cessation. Again, the actual focus depends on the needs of the practice population and involves collaboration with municipal public health authorities.
Support for Care Improvement and Practice Change Even though insurers are still adapting to their new role to initiate practice change, it is clear that the introduction of universal private insurance has created a culture of practice innovation. This has resulted in more prevention and a broader scope of practice in including more diagnostic and surgical procedures and delivery of more care for chronic conditions through primary care. Another factor for change has been the collaboration of (large) groups of family practices in cooperatives to contract support facilities jointly, for example, laboratory facilities to measure pulmonary function in combination with expert advice on diagnosis and management ${ }^{14}$ and support for the management of diabetes mellitus. The ability to identify improvements in the outcome of care for the patient population makes it possible to seek financial support by insurers.

\section{Incentives to Change Quickly}

Two mechanisms have been put in place to make sure that changes can be made quickly. First, the ability of practices to negotiate directly with an insurer for care plans that are relevant for the practice population. This tailor-made approach avoids the bureaucracy to revise programs collectively for all practices and all patients in the country. Another is the link of primary care to municipal health authorities that control the public health budget. $^{2}$ Again, this makes it possible to respond directly to the needs of local communities, for example, initiatives of local practices, the municipality, and insurers to prevent and manage childhood obesity. ${ }^{15}$

\section{How Has Payment for Primary Care Changed to Support New Models?}

The major change has been the introduction of private insurance, with insurers acting as patients advocates. This covers all essential curative care that has stood the test of efficacy. ${ }^{2,5,10}$ All insured patients contribute a flat rate premium and an income-dependent contribution. Health plans are obliged to cover primary care. Health insurers pay FPs a capitation fee for patients on their list (70\% of the overall practice income), and 30\% separately as fee for service. Specialists and hospitals are paid for the actual services that have been provided through a Diagnosis and Treatment Combination. ${ }^{2}$ Practice consortia are contracted to provide chronic 
care management and support the implementation of evidence-based guidelines, ${ }^{10}$ thus providing "accountable care." Practices that fail to meet these standards may be excluded from the consortium. This combination of blended payments for primary care, fee-for-service for specialty care, and payments for chronic care management is a recent change and will require evaluation to know whether or not it is fulfilling the personal and population aims for which it was created. It is an important experiment and social contract.

\section{Strategies for Quality/Safety}

The DCGP introduced a program of guideline development and implementation in $1989,{ }^{10}$ and this program continues to manage the process of quality and safety improvement. To date, 90 guidelines for FPs and 50 interdisciplinary guidelines (primary carehospital care collaboration) have been developed in parallel with related educational programs, patient information, integration with an electronic prescription system, information technology support, and a system to support related referrals.

This quality improvement guideline program was developed in collaboration with university departments of primary care. There is no coordination between these players other than that the College formulates through its guidelines the framework of best practice to which providers and consortia will refer. College guidelines serve as a point of reference for clinical governance. This collaboration supports a large, related primary care research effort ${ }^{6}$ of the Medical Research Council. ${ }^{7}$ This investment in primary care research is seen as important for answering questions that matter in primary care and for improving understanding of quality improvement. University practice-based research networks ${ }^{8}$ serve as the research and development arm for practice innovations. This relationship led to the formal establishment of an Academic Institute of Quality in Health Care. $^{16}$

In 2006 the DCGP developed a practice accreditation program ${ }^{11}$ that put practices through an intensive 3-year process of review of their structures, processes, and outcomes of care, which were assessed against prevailing external criteria/standards. Practices use feedback reports to develop programs for quality improvement. To date, $40 \%$ of the family practices have achieved accreditation.

Collaboration with the quality institutes of the other medical disciplines ${ }^{17}$ has resulted in profes- sional leadership in quality and safety. As a consequence, the professions' innovations have been able to drive quality and challenge insurers to support adoption with financial incentives. To date there have been a number of examples of practices that implement innovative changes for the sake of incentives alone, but their numbers are few. By and large, professional considerations have dictated the adoption of new practice.

\section{Information Technology}

All FP practices use an EMR. The DCGP basic requirements for EMRs result in consistency between various record systems and their capacity to share information. Every system uses the International Classification of Primary Care for diagnoses and care coding. ${ }^{18}$ This facilitates data exchange, even when patients are referred into specialty services or hospitals, and is used to develop decision support tools at the point of care. ${ }^{19}$ Information exchanges between FP practices and hospitals are electronic, enhancing patients' choice and reducing waiting time. Experiments are underway to link EMRs of primary care directly with hospitals and community pharmacists. Citizens generally welcome this, though current privacy regulations hamper their introduction.

\section{Shared Support Systems for Multiple Clinics, Populations, or Regions}

Patient registries make it possible to define the population under care, irrespective of whether patients actually come to the practice. Monitoring and management of this registered population increases delivery of preventive and proactive care, for example, increased rates of flu vaccination, ${ }^{20}$ cervical cancer screening, ${ }^{21}$ cardiovascular risk management, ${ }^{22}$ and health promotional actions in deprived areas. $^{23}$

\section{Failures and Modifications}

The introduction of a fully private health insurance was accompanied by high expectations of market mechanisms to lower costs while securing quality. Five years into the new system, the jury is still out regarding whether this is happening. There are no indications yet that the system contains health care costs, and most political decisions have been directed to control or correct market effects by imposing caps on the agreed costs or by restricting providers in their range of services. 
The growth of independent, single-health issue clinics (eg, for acne, menopause, or men's health) that bypass primary care resulted in a rise of costs. ${ }^{24}$ This has triggered more general concerns that hospitals may work to increase direct access. Because that is expected to cause more rapid growth in costs, preemptive policy measures have strengthened the referral and gate-keeping function of FPs and put barriers on hospital access. Although this may seem at odds with the general interest in returning to marketdriven health care, it is recognized that direct access to hospital services is contrary to evidence-based care and increases unnecessary care rather than being responsive to population needs. Introduction of market mechanisms raised fears that this would stimulate medical consumerism. Thus far, increased use of unnecessary care has only occasionally been observed in primary care.

More grave are the concerns about the lack of coherence in the system and the ability to collaborate. An impressive example is the poor outcome of maternity care ${ }^{25}$ because of rifts between midwives in primary care and obstetricians in secondary care. Despite the examples of success mentioned earlier, the integration of public health and primary care is slow to develop, with variation in success; it is not going as well as was hoped. In line with this are the problems of connecting health care and welfare to deal more effectively with social problems and prevent their medicalization.

\section{Things the United States Has Not Considered in Reform}

An important factor in the drive for primary care reform is the ownership of this process by the profession. Many of the fruits of reform in the United States, such as technical support and incentives for EMR adoption and experiments with new care models, have their value, but they cannot replace the internalizing of professional primary care values $^{5,13}$ and the support of the capacity for the development of knowledge, research, teaching, and organization of primary care. The role of the DCGP is critical to the advancement of quality and safety in primary care and for obtaining support from insurers for ongoing innovation and practice change. It is not clear yet if the Dutch insurance experiment will work, but the blending of payments for primary care, retention of fee-for-service for specialty care, and payments to support integration with public health will surely hold lessons. Like- wise, insurance company investments in communitybased health services and their connections to primary care also will be worth watching. Practices' patient registries and population management benefits already have been well evaluated and are worth replicating in the United States.

\section{Recommendations for US Primary Care}

From this experience, we would like to present five recommendations for the United States. The first relates to the experiences with private insurance. Based on the Dutch experiences, a market-oriented private insurance model is compatible with thriving primary care, provided that the insurance is all inclusive, in particular of the most vulnerable in society. Insurance plans should adhere to the principles of a primary care lead of the health care system, including the principle of navigating or gate-keeping access to more specialized services.

The second is the concept of patient panels or practice lists. This strengthens continuity of care and provides the capacity and incentive to focus on community health. It also makes it possible to focus on and respond to population needs and interact with public health and social services.

The third is the need to reward collaboration within primary care and between primary care, hospital care, and public health. Turning borders between professionals from segregation lines into meeting places should be a priority in finance and reimbursement.

The fourth is to base funding on incentives to stimulate primary care professionals to exert their passion and expertise, rather than to control their performance. Professional self-confidence is the strongest pushing power for a well-functioning health care system. This begs for substantial support for research, education, and development of primary care.

The fifth is to base the health informatics system on primary care informatics. This requires health information beyond diagnosis, such as the symptom and episode information provided by the International Classification of Primary Care, ${ }^{15,21}$ a validated and tested system capable of supporting point-of-care decision making.

With these recommendations, we trust it will be possible to help the United States obtain what is urgently needed-better health for its citizensthrough better use of primary health care. 


\section{References}

1. De Maeseneer J, Moosa S, Pongsupap Y, Kaufman A. Primary health care in a changing world. Br J Gen Pract 2008;58:806-9.

2. Schäfer $W$, Kroneman $M$, Boerma $W$, et al. The Netherlands: health system review. Health Systs Transit 2010;12:v-xxvii, 1-228.

3. Cardol M, Dijk L, Jong JD, de Bakker DH, Westert GP. Tweede nationale studie naar ziekten en verrichtingen in de huisartspraktijk. Huisartsenzorg: wat doet de poortwachter? Utrecht, Bilthoven: NIVEL, Rijksinstituut Volksgezondheid en Milieu; 2004.

4. Mackenbach JP. The feathers of Icarus [in Dutch]. Rotterdam: Erasmus University; 1992.

5. Health Council of the Netherlands. European primary care. Publication no. 2004/20E. The Hague: Health Council of the Netherlands; 2004. Available at http:// www.gezondheidsraad.nl/sites/default/files/summary\% 20primary\%20care\%20final.pdf. Accessed February 1, 2011.

6. The Netherlands School of Primary Care Research (CaRe) [homepage]. Available at http://www. researchschoolcare.nl/. Accessed March 8, 2011.

7. The Netherlands Organization for Health Research and Development (ZonMw). Program Primary Focus. http://www.zonmw.nl/en/programmes/primaryfocus/programme/. Accessed January 31, 2012.

8. Weel $\mathrm{C}$ van. Longitudinal research and data collection in primary care. Ann Fam Med 2005;3:S46S51.

9. Glanville J Kendrick T, McNally R, Campbell J, Hobbs FD. Research output on primary care in Australia, Canada, Germany, the Netherlands, the United Kingdom, and the United States: bibliometric analysis. BMJ 2011;342:d1028.

10. Lugtenberg M, Zegers-van Schaick JM, Westert GP, Burgers JS. Why don't physicians adhere to guideline recommendations in practice? An analysis of barriers among Dutch general practitioners. Implement Sci 2009;4:54.

11. Nederlands Huisartsen Genootschap. Dutch College of General Practitioners practice accreditation [in Dutch]. Available at http://nhg.artsennet.nl/kenniscentrum/ k_implementatie/NPA.htm. Accessed November 6, 2011.

12. van Uden CJ, Giesen PH, Metsemakers JF, Grol RP. Development of out-of-hours primary care by general practitioners (GPs) in The Netherlands: from small-call rotations to large-scale GP cooperatives. Fam Med 2006;38:565-9.

13. Wonca Europe. The European definition of the general practitioner/family physician. 2005. Available at http://www.woncaeurope.org/Web\%20documents/ European\%20Definition\%20of\%20family\%20medicine/ Definition\%202nd\%20ed\%202005.pdf. Accessed April 15, 2011.
14. Bemt L van den, Schermer TJR Smeele IJM, Boonman-de Winter LJM, Boxem T van, Denis J, Grootens-Stekelenburg JG, Grol RPTM, Weel C van. An expert-supported monitoring system for patients with chronic obstructive pulmonary disease in general practice: results of a cluster randomised controlled trial. Med J Aust 2009;191:249-54.

15. Langens F, Dapper T, Nuboer R, Weel C van, Binsbergen $\mathrm{J}$ van. Co-morbidity obese children in family practice in The Netherlands: the results of a pilot study. Fam Pract 2008;25(Suppl 1): i75-8.

16. Scientific Institute for Quality in Health Care, Radboud University Nijmegen [homepage]. Available at http:// www.wokresearch.nl/ContentFront/DefaultStart. aspx. Accessed March 8, 2011.

17. Dutch Institute for Health Care Improvement CBO [homepage]. Available at http://www.cbo.nl/en/. Accessed March 8, 2011.

18. Wonca International Classification Committee. International classification of primary care. 2nd edition. Oxford: Oxford Press; 1998.

19. Lamberts H, Okkes I. Why use ICPC on a routine basis? The usefulness of routine data collected with ICPC for daily practice and clinical decision making. In: Phillips RL, Klinkman M, Green LA, eds. Harmonizing Primary Care Clinical Classification and Data Standards. Conference Report. Washington, D.C.: The Robert Graham Center; 2008.

20. Jansen AG, Sanders EA, Nichol KL, van Loon AM, Hoes AW, Hak E. Decline in influenza-associated mortality among Dutch elderly following the introduction of a nationwide vaccination program. Vaccine 2008;26:5567-74.

21. Palm BT, Kant AC, van den Bosch WJ, Vooys GP, van Weel C. Preliminary results of a general practice based call system for cervical cancer screening in The Netherlands. Br J Gen Pract 1993;43:503-6.

22. van den Donk M, Bobbink IW, Gorter KJ, Salomé PL, Rutten GE. Identifying people with metabolic syndrome in primary care by screening with a mailed tape measure: a survey of 14,000 people in the Netherlands. Prev Med 2009;48:345-50.

23. El Fakiri F, Hoes AW, Uitewaal PJ, Frenken RA, Bruijnzeels MA. Process evaluation of an intensified preventive intervention to reduce cardiovascular risk in general practices in deprived neighbourhoods. Eur J Cardiovasc Nurs 2008;7:296-302.

24. Netherlands Health Care Authority. Market scan care costs medical specialists [in Dutch]. Available at http:// www.nza.nl/104107/105773/354532/Marktscan_ medisch_specialistische_zorg_2011.pdf. Accessed November 6, 2011.

25. Richardus JH Graafmans WC Verloove-van Horick SP Mackenbach JM. The perinatal mortality rate as an indicator of quality of care in interntional comparisons Med Care 1998 36: 54-66. 